\title{
O ENSINO DE MORFOLOGIA NA EDUCAÇÃO BÁSICA: ALGUMAS REFLEXÕES E PROPOSTAS
}

\author{
MORPHOLOGY TEACHING IN BASIC EDUCATION: SOME \\ CONSIDERATIONS AND PROPOSALS
}

Fábio Araújo Oliveira ${ }^{1}$

\begin{abstract}
RESUMO
Neste trabalho, buscamos refletir sobre a cena contemporânea do ensino de morfologia no Brasil, na educação básica, e, a partir daí, propor atividades que privilegiem o funcionamento da gramática no texto. O nosso trabalho está inserido no campo da Linguística Aplicada, por ser uma área interdisciplinar que aborda questões de ensino e aprendizagem de línguas. Nesse sentido, refletimos sobre contribuições da Linguística Textual e da Análise do Discurso para teorias e documentos que provocaram uma mudança na perspectiva de compreender o ensino de gramática. Concluímos que há um descompasso entre teorias pedagógicas e práticas de ensino quanto ao trabalho com a gramática na escola, inclusive no campo da morfologia, por isso se faz necessário contribuir com reflexões e propostas nessa área.
\end{abstract}

PALAVRAS-CHAVE: Ensino de gramática; Morfologia; Linguística Aplicada; Ensino De Língua Portuguesa.

\section{ABSTRACT}

This academic paper seeks to analyze the current situation of morphology teaching in Brazilian Basic Education in order to propose contextualized functional grammar activities. This study belongs to the field of Applied Linguistics - an interdisciplinary field that includes issues in language teaching and learning. In this regard, this study assesses the contributions of Text Linguistics and Discourse Analysis to the theories and papers that stirred a change in the way we may understand grammar teaching approaches. Our conclusion is that there is a gap between theory and practice of teaching grammar in schools, including the field of morphology, what creates a need for considerations and proposals related to this field.

KEYWORDS: Grammar teaching; Morphology; Applied Linguistics: Portuguese Language Teaching.

\section{INTRODUÇÃO}

A morfologia da Língua Portuguesa é ensinada em todos os anos do ensino básico, buscando considerar, de forma generalizante, as diferenças e peculiaridades dos níveis de aprendizagem ao longo desse processo. Os conteúdos de morfologia dos currículos de ensino coincidem com os conteúdos da chamada gramática normativa, ou gramática tradicional, a saber: classes de palavras (substantivo, artigo, adjetivo, numeral, pronome, verbo, advérbio, preposição, conjunção e interjeição), estrutura e formação de palavras.

Entretanto, para ensinar gramática, não é suficiente saber gramática normativa. No caso do ensino de morfologia especificamente, vamos abordar neste artigo a questão da formação de

\footnotetext{
${ }^{1}$ Fábio Araújo Oliveira é escritor e professor adjunto de Linguística e Língua Portuguesa do Departamento de Ciências Humanas - Campus V da Universidade do Estado da Bahia-UNEB. Email: faoliveira@uneb.br
} 
palavras, considerando a que conhecimentos específicos o professor de Língua Portuguesa deve ter acesso para tornar eficiente a sua prática de ensino.

Este artigo se subdivide em 4 seções, além da introdução. Na seção 1, abordamos uma breve história dos estudos linguísticos em morfologia, para revisarmos o que foi produzido de mais importante na área durante várias décadas de pesquisa. $\mathrm{Na}$ seção 2 , abordamos o ensino de morfologia na educação básica, diagnosticando-o na atualidade e refletindo sobre teorias contemporâneas que fundamentam a prática de ensino de gramática. $\mathrm{Na}$ seção 3 , analisamos atividades de morfologia e propomos alternativas para um ensino mais eficiente na área. Por fim, na seção 4, apresentamos nossas conclusões a respeito do assunto abordado.

\section{Breve história da morfologia}

A palavra morfologia vem do grego: morfo (morfhê) significa forma, e logia (logos) significa estudo. Assim, em sua origem morfologia é o estudo da forma. Várias ciências fazem estudos morfológicos. Em Linguística, a morfologia é o estudo da forma da palavra.

O termo morfologia aparece no século XVIII, na perspectiva do Historicismo (Gramática Comparada, Filologia Comparada ou Linguística Histórica e Comparada). Com o Historicismo surgem estudos da linguagem que comparavam línguas na tentativa de encontrar uma língua considerada mãe.

É nesse contexto que o termo morfologia aparece. Segundo Rosa (2003:31), as palavras continuam no centro da investigação, mas o que se enfatiza são os estudos históricos comparativos; "a busca das formas básicas, originárias das palavras, pertencentes ao protoindo-europeu”. Nessa busca pelo processo de evolução das línguas, emerge o interesse pela estrutura interna da palavra e surge uma nomenclatura designativa de tal estrutura (raiz, radical, tema). (BOTELHO: 2007, p 03)

Antes disso, entretanto, já se fazia o estudo da palavra na chamada gramática tradicional.

Tal perspectiva tem origem nos estudos filosóficos greco-latinos e define-se pela preocupação tanto com a relação entre a lógica e a linguagem, quanto com a descrição e fixação de paradigmas e com as questões de regularidades e irregularidades da língua. A unidade básica é, como vimos, a palavra, que segue um determinado esquema de categorização (classes morfológicas) e se organiza em paradigmas (modelos de variação como declinação, conjugação). Não se estuda, nessa tradição, a constituição interna dos vocábulos, os quais são abordados em termos de letras e sílabas até por volta do século IX. (ROSA: 2002, 28).

No princípio do século XX, surge uma nova ciência, a Linguística, sacudindo o pensamento ocidental. O marco desse surgimento é a obra do linguista suíço Ferdinand de Saussure, Curso de linguística geral, publicada pela primeira vez em 1916.

A Lingüística saussuriana, no início do século XX, impõe-se como uma forte adversária da vertente de estudos histórico-comparativos que domina o século anterior. Para Saussure, a língua é um sistema e, para se compreender o valor de uma unidade lingüística, é preciso analisá-la em um determinado momento, dentro dos limites de uma comunidade lingüística, ou seja, em uma perspectiva sincrônica. (BOTELHO: 2007, p 03)

Paralelamente à vertente europeia do Estruturalismo, surge uma outra, conhecida como Estruturalismo norte-americano, cujos principais autores foram Edward Sapir e Leonard Bloomfield. Se a palavra permanece no centro da proposta saussuriana (o signo é a palavra), para a vertente americana do Estruturalismo o morfema é o elemento central. 
No afã de descrever as línguas, os estruturalistas chegaram ao conceito de morfema, que definiremos provisoriamente como "a menor unidade significativa da palavra". (...) Para o que nos interessa no momento, podemos dizer que a visão estruturalista desenvolveu com bastante rigor as técnicas de depreensão dos morfemas e essa foi a sua preocupação básica como movimento lingüístico. Em síntese, o estruturalismo preocupou-se em: a) fazer a segmentação dos morfemas; b) proceder à classificação dos morfemas. (ROCHA: 2008, p. 27)

Nessa perspectiva, a morfologia praticada em grande parte do século XX é uma morfologia baseada no morfema, na análise sintagmática da palavra. Entretanto, em meados desse século, surge o Gerativismo, introduzindo uma nova concepção nos estudos da linguagem, muito diferente da vertente anterior. O Gerativismo, mesmo sem romper com a tradição estruturalista, não segue o mero descritivismo dessa teoria da língua (segmentação, comparação e classificação dos enunciados de uma língua); indo por outros caminhos, ele objetiva construir uma teoria linguística de natureza explicativa, ou seja, explorando o que é o conhecimento linguístico e como tal conhecimento se desenvolve nos indivíduos.

Na gramática tradicional, assim como no estruturalismo, a morfologia derivacional é definida como a parte da gramática de uma língua que descreve a formação e a estrutura das palavras. Numa abordagem gerativa, podemos dizer que a morfologia derivacional é a parte da gramática que dá conta da competência do falante nativo no léxico de sua língua. (BASÍLIO: 1980, p. 07)

O Gerativismo inova os estudos linguísticos e morfológicos ao postular que a competência de um falante em relação ao léxico de sua língua possibilita que o sujeito falante reconheça as palavras de sua língua, rejeite outras, saiba relacionar itens lexicais ou perceber a estrutura de um vocábulo (ROCHA: 2003, p. 30).

Todo esse conhecimento resumido aqui, nesse breve histórico, contribui para o amadurecimento profissional do professor de Língua Portuguesa, e deve ser ativado quando for necessário, não para reproduzi-lo aos seus alunos, mas para orientá-los em seus usos e em suas descobertas e reflexões no campo da morfologia. De que modo? É o que vamos tratar na próxima seção.

\section{O ensino de morfologia na educação básica}

Para um ensino de morfologia bem sucedido, é necessário considerar vários fatores, e um deles diz respeito à formação do professor e ao seu letramento profissional, ou seja, as práticas de leitura e escrita que o auxiliam no exercício profissional.

Ensinar morfologia é ensinar gramática, e para ensinar gramática é necessário tanto um conhecimento de mundo e interdisciplinar, quanto ter acesso a teorias e documentos que orientam ou regulam o ensino de língua. Além disso, é preciso ter acesso a conhecimentos específicos, a saber: a gramática normativa; teorias linguísticas que descrevem a língua e o seu uso, e que normalmente contribuem para aprimorar o conteúdo da gramática normativa; teorias linguísticas sobre a construção do sentido etc. Tais conhecimentos devem ser mobilizados para orientar o aluno no uso da língua oral ou escrita, em suas práticas de escuta, leitura e produção, bem como de reflexão gramatical propriamente dita, considerando o nível de aprendizagem do aluno.

Em termos educacionais, segundo a visão tradicional de ensino de gramática, grande parte do tempo e esforço gasto por professores e alunos durante o processo escolar é destinada ao estudo da metalinguagem de análise da língua(gem), com exercícios contínuos de prescrição gramatical, estudo de regras e resoluções de problemas. Geralmente, os conteúdos linguísticos são apresentados em blocos estanques, cuja 
divisão compartimentaliza a língua como algo descontínuo e desconexo. (SILVA, PILATI, DIAS: 2010, p. 2-3)

Essa visão tradicional de ensino de gramática apenas se utiliza do conhecimento em gramática normativa e ainda é muito praticada contemporaneamente. Nela, o professor de língua procura compreender o conteúdo gramatical e transmite para os seus alunos. No caso do conteúdo formação de palavras, por exemplo, costuma-se analisar linearmente a formação de vocábulos, como é feito na gramática normativa. Eis um exemplo, retirado do site Mundo Educação, que apresenta diversos exercícios sobre os conteúdos do ensino básico:

\section{TEXTO 1}

\section{Questão 3}

Considerando o processo de formação de palavras, relacione a coluna da direita com a da esquerda:

\begin{tabular}{|c|c|}
\hline (1) derivação imprópria & ( ) alfabetização \\
\hline (2) prefixação & () o feito \\
\hline (3) prefixação e sufixação & () pontapé \\
\hline (4) sufixação & () incapaz \\
\hline (5) composição por justaposição & () infelizmente \\
\hline
\end{tabular}

a) $3,4,2,5,1$

b) $2,4,3,1,5$

c) $4,1,5,3,2$

d) $2,4,3,5,1$

e) $4,1,5,2,3$

(Mundo Educação, acessado em 07.05.2010)

Há alguns problemas nessa perspectiva de ensino de gramática. Em primeiro lugar, ela apenas se debruça sobre a forma da língua, e numa perspectiva prescritiva. No entanto, a gramática deve estar a serviço do sentido, da construção do sentido, da interpretação e da produção de textos.

Inicialmente, a Linguística Textual pautada no socio-interacionismo teve grande influência na mudança de paradigma de ensino da Língua Portuguesa, a partir da década de 1980, no Brasil. Conforme Koch (1993), considerando o texto como unidade fundamental de análise, essa teoria linguística se interessa pela linguagem em uso, socializando um conhecimento que ultrapassa os limites da gramática normativa e das teorias em torno da forma da língua. Segundo sua perspectiva, o texto é uma unidade semântica, e os elementos da língua atuam na construção dessa unidade.

A Análise do Discurso também contribuiu muito para uma mudança no paradigma de ensino de Língua Portuguesa a partir da década de 1980, embora com mais timidez do que a Linguística Textual. Para Orlandi (2015), nessa teoria não importa a mera transmissão de informação, e sim a linguagem em funcionamento, que constitui sujeitos e sentidos afetados pela língua e pela história. A sua perspectiva também ultrapassa as fronteiras da gramática normativa e das teorias que estudam a forma da língua. Conforme sua proposta, a língua é condição de possibilidade do discurso.

Em relação ao trabalho com o sentido do/no texto, utilizando principalmente a Linguística Textual ou na Análise do Discurso, em suas mais variadas vertentes, surgiram novas propostas sobre o ensino de língua, principalmente na área da Linguística Aplicada, contrapondo-se a um ensino considerado tradicional. Tais propostas influenciaram a produção de documentos que orientam o ensino de Língua Portuguesa. Nessa nova perspectiva, há um consenso: o trabalho com a língua em uso, através de textos diversos orais e escritos. É nesse contexto que surgem propostas específicas para o ensino de gramática. Uma delas é a da Análise Linguística: 
O termo Análise Linguística foi cunhado por Geraldi em 1984, no artigo "Unidades básicas do ensino de português", parte da coletânea "O texto na sala de aula" (2004b), para denominar uma nova perspectiva de reflexão sobre o sistema linguístico contraposta ao ensino tradicional. Nas bases epistemológicas da proposta estão: a capacidade humana de refletir, analisar, pensar sobre os fatos e os fenômenos da linguagem; e a propriedade que a linguagem tem de poder referir-se a si mesma, de falar sobre a própria linguagem, por intermédio de atividades epilinguísticas e metalinguísticas.

(...)

$\mathrm{Na}$ perspectiva da AL, as atividades escolares devem partir do uso efetivo da língua, entendido aqui como o exercício pleno, circunstanciado e com intenções significativas da própria linguagem, para a reflexão epilinguística e desta para a metalinguística, para, depois, tornar ao uso. Assim, dizemos que a AL configura-se como uma prática de ensino que tem o uso da linguagem como seu ponto de partida e de chegada. (SILVA: 2010, p. 04)

As atividades metalinguísticas já eram feitas anteriormente; a novidade na Análise Linguística está em dar ênfase ao uso da língua, incorporando, para isso, a reflexão epilinguística e considerando a reflexão metalinguística. No entanto, contemporaneamente ainda há muitos problemas relacionados à atuação de professores de Língua Portuguesa no ensino de gramática, principalmente porque eles continuam ensinando gramática considerando predominantemente a reflexão metalinguística. Assim, a análise linguística acaba sendo sinônimo de reflexão metalinguística.

Outra proposta é a de Costa Val (2002), é a da gramática que funciona no texto:

O que estou chamando de gramática do texto e no texto diz respeito ao conjunto de conhecimentos e habilidades dos falantes que lhes possibilita interagir lingüisticamente produzindo e interpretando textos, falados e escritos, nas diversas situações de sua vida; noutros termos, diz respeito ao saber internalizado dos falantes que os habilita a lidar com os recursos lingüísticos - gramaticais - na produção e na compreensão dos textos que circulam nas práticas sociais de linguagem. É a gramática que "funciona" nesses textos. (COSTA VAL: 2002, p. 110)

Também nessa perspectiva de ensino de gramática, parte-se do uso da linguagem, ou seja, da prática de produzir ou interpretar textos, considerando o conhecimento empírico do aluno e, a partir disso, realizando o trabalho de reflexão gramatical de forma planejada. Mesmo assim, os professores predominantemente continuam ensinando gramática privilegiando a reflexão metalinguística, mas fazendo isso a partir do texto. E a gramática do/no texto acaba sendo entendida como reflexão metalinguística no texto, e não em orações produzidas para isso.

A Base Nacional Comum Curricular (BNCC), diretriz de nível federal instituída no Brasil no final do ano de 2018, "dialoga com documentos e orientações curriculares produzidos nas últimas décadas buscando atualizá-las em relação às pesquisas recentes da área e às transformações das práticas de linguagem ocorridas neste século" (BRASIL: 2018, p. 67) Sobre o ensino de análise linguística na escola, o documento diz que:

Se uma face do aprendizado da Língua Portuguesa decorre da efetiva atuação do estudante em práticas de linguagem que envolvem a leitura/escuta e a produção de textos orais, escritos e multissemióticos, situadas em campos de atuação específicos, a outra face provém da reflexão/análise sobre/da própria experiência de realização dessas práticas. Temos aí, portanto, o eixo da análise linguística/semiótica, que envolve o conhecimento sobre a língua, sobre a norma-padrão e sobre as outras semioses, que se desenvolve transversalmente aos dois eixos - leitura/escuta e produção oral, escrita e multissemiótica - e que envolve análise textual, gramatical, lexical, fonológica e das materialidades das outras semioses (BRASIL: 2018, p. 80) 
A BNCC inova ao incorporar, no ensino de língua portuguesa, reflexões e práticas relacionadas às multissemioses e as tecnologias digitais e mantem a perspectiva da análise linguística apresentada por teorias e outros documentos que lhe antecedem.

\section{Reflexões e propostas}

No ENADE 2017 - Letras/ Português Licenciatura, uma questão discursiva exigia dos graduandos que analisassem a função da formação de palavras no texto em questão. Eis um bom exemplo para discutirmos o ensino de morfologia na educação básica, considerando as especificidades dos diferentes contextos e o que foi exposto até o momento neste artigo.

\section{TEXTO 2}

\section{QUESTÃO DISCURSIVA 03}

\section{Esteticar (Estética do plágio) \\ Tom Zé}

Pense que eu sou um caboclo tolo boboca

Um tipo de mico cabeça-oca

Raquítico típico jeca-tatu

Um mero número zero um zé à esquerda

Pateta patético lesma lerda

Autômato pato panaca jacu

Penso dispenso a mula da sua ótica

Ora vá me lamber tradução inter-semiótica

Se segura milord aí que o mulato baião

(tá se blacktaiando)

Smoka-se todo na estética do arrastão

$[\cdots]$

Com base no trecho da letra da música, faça o que se pede nos itens a seguir.

a) Explique a formação dos neologismos "esteticar", "blacktaiando" e "smoka-se".

b) Explique o modo como a formação dos neologismos contribui para a construção de sentidos na letra da música.

$\mathrm{Na}$ questão, além de se solicitar que se faça uma reflexão metalinguística, ou seja, explicar a formação dos neologismos, pede-se também que se analise a função desse processo no texto, que é uma canção. Forma e função trabalhando juntas. Estrutura e acontecimento em ação. É claro que em sala de aula o trabalho poderia ser mais completo, com várias outras atividades, mas aqui serve o exemplo para um debate inicial.

Entendemos que ensinar gramática, na perspectiva de analisar o seu funcionamento no texto, é atuar na interpretação ou na produção textual. Mas não é fazer isso de qualquer forma: é analisar como a língua, a materialidade linguística atua na construção dos sentidos, inclusive de modo que não depende da pura intenção do autor. É relacionar a língua à história, à memória e ao contexto. É trabalhar o sentido. Aqui, o que está em evidência é a função da língua(gem).

Esse trabalho relaciona-se à perspectiva de refletir estritamente sobre a língua, ou seja, de um trabalho de metalinguagem. Nesse sentido, tanto o conhecimento linguístico empírico - o que é aprendido no uso -, quanto o conhecimento linguístico aprendido de modo formal, como o da gramática normativa, devem ser considerados. É o que chamamos de reflexão gramatical. Aqui, o que está em foco é a forma da língua, principalmente em sua norma padrão, considerando o papel da escola.

É desejável que se aproveite o conhecimento empírico do aluno, seus usos linguísticos, reflita-se sobre isso, para então daí poder inserir o estudo de gramática normativa. E para se chegar ao sentido do texto, é importante considerar o funcionamento da língua, da gramática naquele texto, considerando sempre, para isso, o contexto e tudo que ele envolve. 
$\mathrm{Na}$ canção, se blacktaiando e smoka-se são neologismos formados a partir de uma palavra de Língua Inglesa, seguindo as regras de formação e flexão de palavras da Língua Portuguesa. Em se blacktaiando, acrescenta-se o pronome oblíquo átono se, a vogal temática a e o morfema flexional de gerúndio -ndo à base blacktai, que é alomorfia de "black tie", transformando um nome de Língua Inglesa em um verbo pronominal da Língua Portuguesa flexionado no gerúndio (se blacktaiando seria o gerúndio de blacktaiar-se):

[se Pronome + [black tie $]$ Nome + VT + -ndo] Verbo.

Em smoka-se, acrescenta-se o pronome oblíquo átono se e a vogal temática verbal a à base smoke, transformando um nome de Língua Inglesa em um verbo pronominal da Língua Portuguesa, conjugado na terceira pessoa do singular do presente do indicativo (smoka-se seria uma forma do verbo smokar-se):

[ [smoke] Nome $+\mathbf{a}$ Vogal Temática Verbal + se Pronome] Verbo

É importante salientar que o conteúdo da gramática normativa pode apresentar equívocos, por isso se faz necessário uma análise crítica da gramática, a partir de teorias linguísticas que pesquisam sobre o assunto e produzem conhecimento atualizado. Se o professor possui tal conhecimento, ele poderá mediar o processo de ensino-aprendizagem já incorporando tais atualizações, considerando o nível de aprendizagem dos alunos. No caso da formação de palavras, por exemplo, a gramática normativa apresenta uma análise linear para palavras morfologicamente complexas, baseada na depreensão e classificação de todos os morfemas em um mesmo nível do vocábulo, o que é criticado por alguns linguistas, como Basílio, por exemplo.

\footnotetext{
Mais especificamente, a palavra morfologicamente complexa, ou seja, a palavra que contém mais de um elemento, é estruturada basicamente como a combinação de uma base com um afixo. Assim, podemos ter vários níveis ou camadas na estrutura de uma palavra. Vejamos, por exemplo, as palavras centro, central, centralizar, descentralizar, descentralização. A primeira palavra, centro, é constituída apenas pela base, embora se possa considerar que esta apresente uma vogal temática. A segunda palavra, central, é formada pelo acréscimo do sufixo -al à base; a terceira, centralizar, formada pelo acréscimo do sufixo verbalizador -izar à base, constituída pelo adjetivo central; a quarta, descentralizar, é formada pelo acréscimo do prefixo negativo des- à base verbal centralizar e, finalmente, a quinta, descentralização, é formada pelo acréscimo do sufixo substantivador -ção à base descentralizar. (BAŚ́LIO: 1987, p. 14)
}

Essa descrição é puramente metalinguística. É a utilização da língua para explicar a própria língua, utilizando o conhecimento da morfologia, tanto da teoria linguística, quanto da gramática normativa. Esse conhecimento deve fazer parte do letramento profissional do professor de Língua Portuguesa. O aluno do ensino básico poderia fazer uma atividade igual ou semelhante a partir do seu conhecimento linguístico empírico ou do seu conhecimento formal, considerando o seu nível de aprendizagem. Entretanto, ela não é suficiente para interpretar textos, conforme abordamos. É necessário também analisar a função da gramática no texto.

$\mathrm{Na}$ canção de Tom Zé, a formação de neologismos tem uma função, ajuda a construir o sentido do texto. Os neologismos se blacktaiando e smoka-se, por serem formados a partir de uma base que é um nome em inglês, como vimos, ativam uma memória, um já dito, que diz respeito ao valor simbólico que a cultura dos EUA possui diante do mundo, inclusive no Brasil. Além disso, considerando o significado dos radicais, ativam os sentidos de que é preciso estar bem apresentado, transformando-se, ou seja, vestindo-se formalmente para ocasiões especiais, porque a "aparência" importa muito.

Esse outro a princípio faz referência à cultura norte-americana, mas pode ser metáfora do estrangeiro que pretende impor sua cultura como a melhor. Essa outra cultura produz um imaginário no qual quem não faz parte dela, como o eu lírico, é inferiorizado, é um "caboclo tolo boboca". Porém, o eu lírico rejeita tal imaginário: "Penso dispenso a mula da sua ótica". É uma reação ao total assujeitamento à cultura alheia, que pretende se fazer dominante. Como smoke e 
black tie são trajes elegantes, o eu lírico ironiza, mostrando seu lado antropofágico, ou seja, ele se veste elegantemente, como o outro determina o que é elegância, mas não perde sua identidade, pois "Smoka-se todo na estética do arrastão". Arrastão é uma palavra ambígua e metafórica, podendo significar "engodo", ou "assalto coletivo, em que um grupo de pessoas roubam outras por onde passa".

Essa discussão é sintetizada pelo autor como a estética do plágio, criando o verbo esteticar - que já aparece no título-, formado pelo nome estética, acrescido da vogal temática verbal a mais a desinência de infinitivo $\mathbf{r}$ :

[ [estética] Nome $+\mathbf{a}$ Vogal Temática Verbal $+\mathbf{r}$ Desinência Verbal de Infinitivo] Verbo.

Esteticar (Estética do plágio) faz referência a uma ação, a de imitar um modo de vida, uma cultura, a de plagiar o outro; e o plágio falha, tanto de modo ocasional, como de modo intencional. Falha por vários motivos que não são citados no texto, apenas sugeridos; falha porque a imitação nunca é o original. E é nessa falha que há a possibilidade de uma reação.

É importante lembrar que o texto Esteticar ( Estética do plágio) é uma canção, e se formos analisá-la em sala de aula, nas aulas de Língua Portuguesa, é importante considerar também o contexto situacional de sua produção, e não só o contexto histórico, ou seja, ela faz parte de um CD, produzido na década de 1990, e foi escrita por um músico e cantor. Dessa forma, novos sentidos podem ser construídos nesse ato de interpretação.

Como vimos, saber gramática normativa não garante que se saiba trabalhar a gramática funcionando no texto em sala de aula. É preciso mais. É preciso conhecimento de mundo, de análise de textos, de análise de discursos etc. É preciso conhecimento de Literatura, Artes em geral, História, Antropologia, Sociologia etc. É preciso ter um letramento profissional realmente amplo, elástico, com circuito em várias áreas. A perspectiva da gramática funcionando no texto também se aplica para a produção de textos, pelos mesmos motivos que abordamos quanto à interpretação textual.

\begin{abstract}
Assim, o professor de língua precisa ter instrumentos suficientes para trabalhar a gramática funcionando no texto, nos diversos textos, ou seja, precisa saber trabalhar a importância dos itens gramaticais na/para construção de textos, tanto de autores consagrados, quanto de alunos autores e outros escritores. Como consequência de tal abordagem, o aluno deverá refletir sobre gramática primordialmente para interpretar textos orais ou escritos e produzi-los, e não para provar ao professor que sabe teoria gramatical. (OLIVEIRA: 2019, p. 121)
\end{abstract}

A canção "Esteticar (Estética do plágio)" poderia perfeitamente ser trabalhada como sugerimos no ensino médio. A formação de palavras pode ser trabalhada em outros textos no ensino fundamental, na perspectiva da análise do funcionamento da gramática no texto, sempre respeitando o nível de aprendizagem dos alunos. Há muitas palavras em formação que podem ser analisadas, partindo do conhecimento empírico dos alunos e chegando ao conhecimento explícito e formal da gramática normativa. Vejamos situações em que palavras foram criadas para não prejudicar o processo de interação:

\footnotetext{
Situação 1: Pai e filho passeiam pelo terreiro. De repente, o filho vê uma formiga e pisa em cima dela. Como ela permanece imóvel, o filho afirma:

- Pai, a formiga morreu!

Segundos depois, a formiga volta a andar e o filho exclama:

- Pai, a formiga desmorreu! (ROCHA: 2008, p. 21)
}

Nesse texto, a criança criou a palavra desmorreu, obedecendo as regras de formação de palavras da Língua Portuguesa. Perguntas podem ser feitas para aproveitar o conhecimento empírico dos alunos:

1. A palavra desmorreu lembra que outra palavra? 
2. Que parte foi acrescentada à palavra morreu, para formar a palavra desmorreu?

3. O que significa morreu?

4. O que significa desmorreu?

4. Quando acrescentamos a parte des- à palavra morreu, que sentido tem esse pedacinho?

5. Que outras palavras também possuem des- com o significado de negação?

6. No contexto, por que a criança inventou a palavra desmorreu?

Esse é um exemplo de atividade que pode ser feito nos anos iniciais do ensino fundamental, inclusive considerando e valorizando a variação linguística, caso surjam palavras de norma não padrão. Outra atividade são jogos de formação de palavras, em que o aluno encaixa um pedaço (afixos) a outro (radical) para formar vocábulos, possibilitando que ele reflita de forma lúdica sobre a construção das palavras.

A partir dos anos finais do ensino fundamental, pode-se incluir a nomenclatura oficial da gramática normativa, como morfema, radical, prefixo, sufixo etc. Além disso, pode-se fazer pesquisas sobre palavras em formação, inclusive palavras usadas pelos próprios alunos, já que é muito comum a criação de vocábulos em grupos de adolescentes e jovens. Nessas atividades, cabe uma reflexão sobre os sujeitos que usam tais palavras, as situações comunicativas em que elas são empregadas, as finalidades de tal uso, o valor linguístico e social que as expressões possuem etc.

É importante lembrar que a discussão sobre a variação linguística deve fazer parte da abordagem sobre palavras em formação, já que vocábulos podem ser criados em qualquer norma linguística. Trabalhar o ensino de gramática é também trabalhar a variação linguística.

\section{CONCLUSÃO}

O trabalho com morfologia deve ser articulado: reflexão gramatical e gramática funcionando no texto, considerando a variação da língua. A gramática funcionando no texto diz respeito à construção e interpretação do texto, seja ele oral ou escrito, o que envolve mecanismos de coesão e coerência, de produção de sentidos. Envolve também conhecimento de mundo, já que estamos nos referindo à construção de sentidos.

No entanto, o ensino de língua, na perspectiva do funcionamento da gramática no texto, ainda é uma pedra no caminho de muitos professores de Língua Portuguesa, apesar da existência de propostas inovadoras e atualizadas sobre o ensino de gramática. Um dos motivos está na própria formação do professor. Os currículos de Licenciatura em Letras/ Português mais parecem currículos de um curso de bacharelado em Linguística. Os componentes curriculares da área de morfologia, por exemplo, ou abordam predominantemente teoria linguística (morfologia estruturalista e/ou gerativista), ou estão em transição, incluindo timidamente discussões sobre o ensino da língua, e especificamente de gramática. Já os componentes da área de ensino de língua, incluindo os estágios, tendem a priorizar uma abordagem sobre leitura e produção de textos, dando menos espaço para a oralidade e a gramática, mesmo que esta seja útil na leitura e na produção de textos orais e escritos.

Além disso, embora encontremos poucas publicações sobre ensino de gramática, as propostas são predominantemente generalizantes, abordando o ensino como um todo, e ilustrando com um ou outro exemplo específico. E os livros de morfologia, mesmo também direcionados aos professores - como os próprios autores comentam nas apresentações e sinopses das obras-, abordam a pura teoria linguística específica, de acordo com uma vertente eleita.

Outra questão é que os professores de língua precisam manter uma atualização do seu conhecimento a respeito de questões de gramática, tanto da gramática tradicional, quanto da chamada gramática descritiva, e isso nem sempre acontece. A reflexão gramatical é uma etapa importante no ensino de gramática, e a gramática normativa precisa ser analisada com criticidade. 


\begin{abstract}
Em grande parte, a crítica feita à GT vem dos estudos produzidos pela Linguística desde o surgimento dessa ciência. Foi ela que problematizou a GT, em um primeiro momento, através de análises da língua em vários níveis, como se pode observar nas pesquisas feitas em Morfologia, Sintaxe, Fonologia e Semântica, bem como por meio de estudos linguísticos mais contemporâneos, em um segundo momento, como os feitos pela sociolinguística sobre variação e mudança linguística, por exemplo, ou feitos pelas teorias do sentido que extrapolaram os limites da sentença, como a pragmática, a linguística textual e a análise do discurso.

O professor de língua, tendo acesso inclusive a todo esse conhecimento linguístico, deve mediar, de forma consciente e madura, a reflexão linguística do aluno, considerando as especificidades de cada turma. Dessa forma, há dois caminhos, dependendo do nível de escolaridade do aluno: ou o conteúdo gramatical já é apresentado ao aluno com os avanços filtrados pelo professor, ou o professor faz a mediação da análise crítica que o aluno vai fazer. (Oliveira: 2019, p. 114)
\end{abstract}

Além desse conhecimento específico relacionado ao ensino de gramática, em especial ao ensino de morfologia, é necessário um conhecimento amplo, conforme já abordamos, porque estamos tratando de análise da língua(gem) em ação, de construção de sentido. Sabemos que são muitas e distintas as realidades profissionais, socioculturais e econômicas dos professores de Língua Portuguesa do ensino básico, no Brasil, considerando a desigualdade que há em nosso país. Normalmente não são dadas a esses profissionais condições satisfatórias de leituras e pesquisas diversificadas, de lazer e de acesso a variadas formas de arte. As aulas são muitas, o dinheiro é pouco, e o tempo é menor ainda. Isso também prejudica a sua formação, a sua atualização, enfim, o seu letramento profissional, o que tem efeitos na prática em sala de aula.

Esperamos, com este artigo, ter provocado uma reflexão pertinente a respeito do ensino de morfologia. Quando enxergamos os problemas e os compreendemos, torna-se mais fácil buscar caminhos para sua solução. Além disso, esperamos também ter contribuído com propostas para um ensino mais eficiente na área. Que lutemos por uma educação transformadora! É o que desejamos, porque acreditamos na força da educação.

\title{
REFERÊNCIAS BIBLIOGRÁFICAS
}

BASÍLIO, Margarida. Estruturas lexicais do português: uma abordagem gerativa. Petrópolis: Vozes, 1980.

BASÍLIO, Margarida. Teoria lexical. São Paulo: Ática, 1987.

BRASIL. Base Nacional Comum Curricular: educação é a base. Brasília: MEC, 2018. Disponível em: www.basenacionalcomum.mec.gov.br, acessado em 05 de abril de 2020.

BOTELHO, Laura Silveira. Breve apresentação histórica dos estudos Morfológicos e suas correntes lingǘsticas. Revista Eletrônica da Faculdade Metodista Granbery. N. 3, JUL/DEZ 2007

file:///C:/Users/COMPAQ/Documents/textos $\% 20$ ensino $\% 20 \mathrm{de} \% 201 \% \mathrm{C} 3 \%$ ADngua/Hist $\% \mathrm{C}$ 3\%B3ria $\% 20 \mathrm{da} \% 20$ Morfologia.pdf, acessado em 04 de abril de 2020

COSTA VAL, Maria da Graça. A gramática do texto, no texto. In: Rev. Est. Ling., Belo Horizonte, v.10, n. 2, p.107-133, jul./dez. 2002

ENADE 2017 Letras/ Português Licenciatura. Disponível em file:///C:/Users/COMPAQ/Documents/enade/31 LET POR LICENCIATURA BAIXA.pd f, acessado em 07.05.2020 
GERALDI, J. W. Unidades básicas do ensino de português. In: GERALDI, J. W. (Org.). O texto na sala de aula. 3. ed. São Paulo: Ática, 2004b. p. 59-79.

$\mathrm{KOCH}$, Ingedore Grunfeld Villaça. Desvendando os segredos do texto. São Paulo: Cortez, 2002.

Mundo Educação. Disponível em https://exercicios.mundoeducacao.bol.uol.com.br/, acessado em 07.05.2020

OLIVEIRA, Fabio Araújo. O ensino de gramática: reflexões e propostas. Revista do GELNE, v. 21, n. 2, p. 112-125, 5 ago. 2019

ORLANDI, Eni P. Análise do discurso: princípios e procedimentos. $12^{\mathrm{a}}$ ed. Campinas, SP: Ponres Editores, 2015.

ROCHA, Luiz Carlos de Assis. Estruturas morfológicas do português. $2^{a}$ ed. São Paulo: Editora WMF Martins Fontes, 2008.

ROSA, Maria Carlota. Introdução à morfologia. 2. ed. São Paulo: Contexto, 2002.

SAUSSURE, Ferdinand de. Curso de Linguística Geral. 22ª ed. São Paulo: Editora Cultrix, 2000

SILVA, Kleber Aparecido da, PILATI, Eloisa, DIAS, Juliana de Freitas. O ensino de gramática na contemporaneidade: delimitando e atravessando as fronteiras na formação inicial de professores de língua portuguesa. In: RBLA, Belo Horizonte, v. 10, n. 4, p. 975-994, 2010

SILVA, Noadia Íris da. Ensino tradicional de gramática ou prática de Análise Linguística: uma questão de (con)tradição nas aulas de português. In: Revista Brasileira de Linguística Aplicada. vol.10 no.4 Belo Horizonte 2010 